\section{Retrieval of high-resolution nearshore bathymetry from Sentinel-2 twin multispectral imagers using a multi-scene approach}

\author{
Surisetty V. V. Arun Kumar ${ }^{1, *}$, \\ Ch. Venkateswarlu ${ }^{2}$, B. Sivaiah ${ }^{2}$, \\ K. V. S. R. Prasad ${ }^{2}$, Rashmi Sharma ${ }^{1}$ and \\ Raj Kumar ${ }^{1}$
}

${ }^{1}$ Earth, Ocean, Atmosphere, Planetary Sciences and Applications Area, Space Applications Centre (ISRO), Ahmedabad 380 015, India

${ }^{2}$ Department of Meteorology and Oceanography,

Andhra University, Visakhapatnam 530 004, India

Determining nearshore bathymetry by traditional surveying methods is a challenging task as it involves huge costs and efforts. Most of the coastal shallowwater zones worldwide either remain unmapped or not updated. Bathymetry estimations from optical satellite imageries have been increasingly implemented as an alternative tool for traditional bathymetry surveys. In this study, we examine the usefulness of freely available, five-day revisit and relatively highresolution Multi Spectral Instruments (MSI) on-board Sentinel-2A and 2B twin satellites. A process workflow has been developed which automatically incorporates a robust atmospheric correction through ACOLITE software and multi-scene compositing of several scenes to improve the reliability and no data gaps. Two study sites in India are explored owing to their variability in submarine morphology. High-resolution bathymetry maps are generated through a log-ratio transform model calibrated with minimal in situ data from the jet ski soundings. The satellite-derived bathymetry obtained has an overall bias of $\mathbf{- 0 . 0 1}$ and $0.02 \mathrm{~m}$, and root mean square error of 1.09 and $0.93 \mathrm{~m}$ respectively, at two study sites up to $15 \mathrm{~m}$ depth. The consistency in bathymetry retrieval indicates a potential for automated application for the benefit of operational and scientific studies. These high-resolution maps capture small-scale nearshore features like sandbars and rip channels, which are of prime importance for coastal and beach managers.

Keywords: Optical remote sensing, multispectral imagers, nearshore bathymetry maps, rip channel, twin satellites.

ACCURATE and high-resolution bathymetry is essential for a wide range of applications, including coastal navigation $^{1}$, harbour dredging activities ${ }^{2}$, coastal ecosystem management ${ }^{3}$, fishing ${ }^{4}$, mineral exploration ${ }^{5}$, natural hazards impact ${ }^{6}$, driving coastal modelling ${ }^{7}$, etc. Nearshore region is most sensitive to the effects of climate change such as coastal erosion, subsidence and sea-level

*For correspondence. (e-mail: arunkumar@sac.isro.gov.in) rise $^{8}$. Therefore, determining bottom depths closer to the shore is of utmost importance. Currently, two most widely used techniques for acquiring nearshore bathymetry data are hydrographic boat surveying with single or multibeam echo sounder and airborne light detection and ranging (lidar). However, the cost and logistical difficulties in obtaining nearshore bathymetry using these methods limit these surveys to narrow coastal stretches.

Satellite-derived bathymetry (SDB) approach is emerging as a cost-effective alternate methodology to provide accurate mapping over a wide area, rapidly and efficiently. Many researchers worldwide estimated SDB by wavefield inversion approach from Synthetic Aperture Radar (SAR) imagery ${ }^{9-11}$ and multispectral data ${ }^{12-14}$ in the coastal waters. The most important advantage of optical imagery is that it can be used to retrieve depths close to the shoreline (under calm sea state and clear waters). Therefore it is possible to map the underwater small-scale features accurately than using SAR. This study demonstrates the ability of high spatial and temporal resolution Sentinel-2A and 2B satellites to generate accurate nearshore bathymetry maps.

The study sites are Rushikonda $\left(17^{\circ} 46^{\prime} 54^{\prime \prime} \mathrm{N}\right.$, $\left.83^{\circ} 23^{\prime} 07^{\prime \prime} \mathrm{E}\right)$ designated as region of interest-1 (ROI-1) and RK Beach $\left(17^{\circ} 42^{\prime} 52^{\prime \prime} \mathrm{N}, 83^{\circ} 19^{\prime} 29^{\prime \prime} \mathrm{E}\right.$, ROI-2) in Visakhapatnam, India (Figure $1 a-d$ ). Rushikonda is a bay with a flat bottom and contains protruded rocky outcrops in the southern side protecting it from high waves. RK Beach (located $8 \mathrm{~km}$ from Rushikonda) is an open coast with steep beach slope often exposed to high waves, especially during monsoon and cyclones. Rushikonda and RK Beach are prone to severe erosion and dangerous rip currents $^{15}$. Thus it is necessary to regularly monitor the nearshore bathymetry at these beaches.

Acoustic surveys were carried out on 24 and 25 October 2018 at Rushikonda and RK Beach respectively, using a modified jet ski with a $200 \mathrm{kHz}$ CEESCOPE $^{\mathrm{TM}}$ echo-sounder and a $10 \mathrm{~Hz}$ Novatel OEMStar L1/L2 GNSS receiver (CEE HydroSystems). The key benefits of using a jet ski are: it can be quickly launched from the beach itself (no berthing is required), is easy to carry to the desired location, it can reach as shallow as $0.5 \mathrm{~m}$ depth where traditional boats cannot reach and can perform even in rough sea condition and in the surf zone. The vertical accuracy of the echo-sounder is $1 \mathrm{~cm} \pm 0.1 \%$ of depth and the horizontal accuracy of position from GNSS is around $\pm 0.5 \mathrm{~m}$. The echo-sounder is equipped with an inertial motion unit (IMU) sensor to record the three-dimensional motion. This sensor provides an accuracy of $\pm 0.1^{\circ}$ in roll and pitch over $360^{\circ}, 1^{\circ}$ in the heading and $\pm 5 \mathrm{~cm}$ in the heave. The impact of waves has been accounted for by correcting the echo-sounder depths using the heave data from the IMU sensor following the procedure adopted from Dugan et al. ${ }^{16}$. The upward (downward) motion of the jet ski and the presence of waves were subtracted (added; in metres) to the sounding 

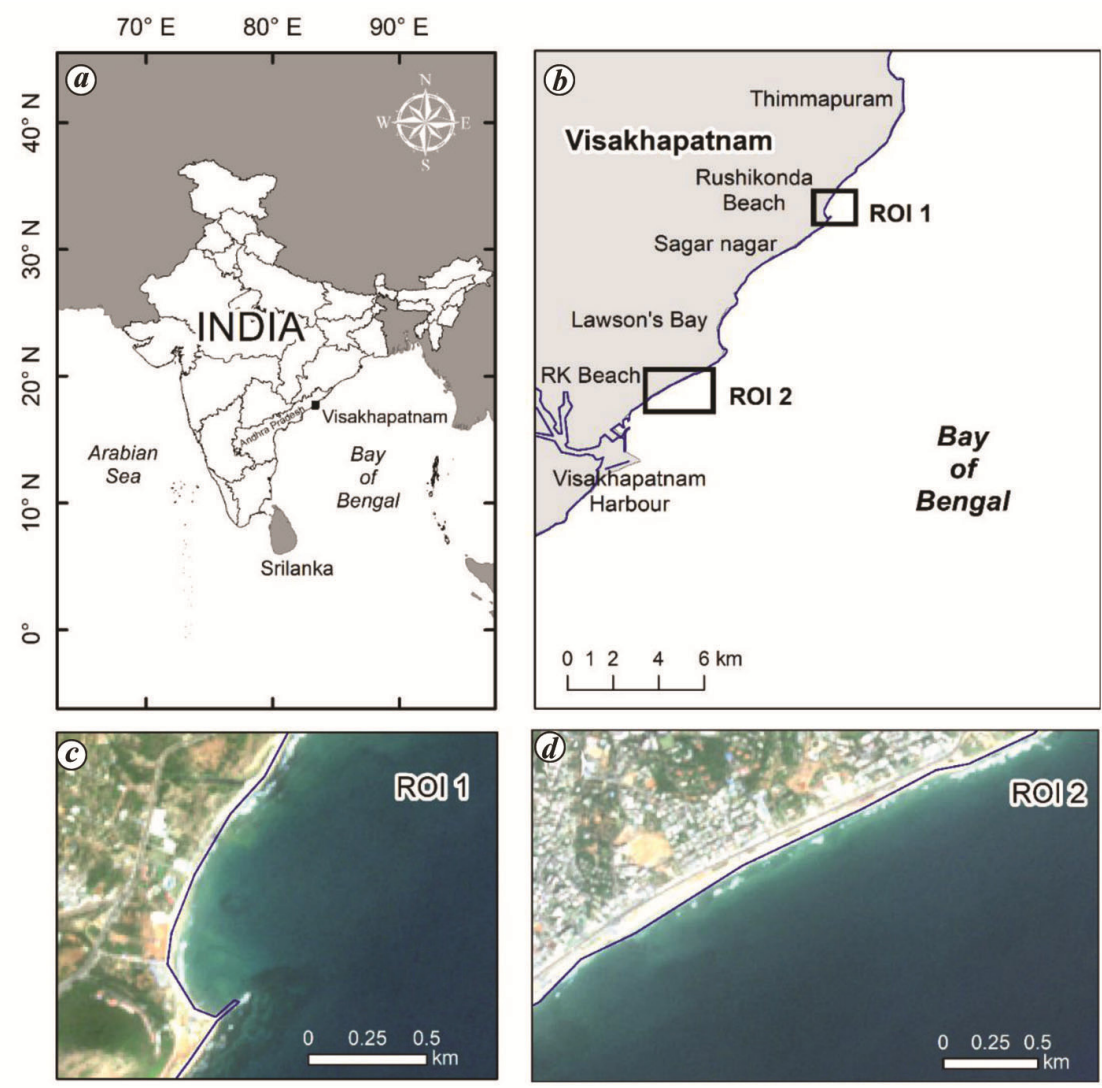

Figure 1. $\boldsymbol{a}$, Location map of India. $\boldsymbol{b}$, Visakhapatnam coastal area with the regions of interests (ROI). $\boldsymbol{c}$, Rushikonda (ROI 1). $\boldsymbol{d}$, RK Beach (ROI 2) represented by Sentinel-2B RGB image acquired on 24 November 2018.

Table 1. Details of Sentinel-2 (S2A and S2B) satellite products used in the study. The tide heights are with respect to mean lowest low water level (MLLW) at Visakhapatnam Harbour $\left(17^{\circ} 41.00^{\prime} \mathrm{N}, 83^{\circ} 17.00^{\prime} \mathrm{E}\right)$

\begin{tabular}{lccc}
\hline Satellite & $\begin{array}{c}\text { Acquisition } \\
\text { date } \\
\text { mission }\end{array}$ & $\begin{array}{c}\text { Scene time } \\
\text { (UTC) }\end{array}$ & $\begin{array}{c}\text { Tide height } \\
(\mathrm{m})\end{array}$ \\
\hline S2B_MSI & $2018-10-05$ & $04: 46: 59$ & 1.10 \\
S2A_MSI & $2018-10-20$ & $04: 48: 21$ & 1.15 \\
S2B_MSI & $2018-10-25$ & $04: 48: 49$ & 1.21 \\
S2A_MSI & $2018-10-30$ & $04: 49: 21$ & 1.13 \\
S2B_MSI & $2018-11-24$ & $04: 51: 19$ & 1.23 \\
S2B_MSI & $2018-12-24$ & $04: 52: 19$ & 1.30 \\
\hline
\end{tabular}

Source: Indian National Centre for Ocean Information Services, Hyderabad.

depth data to correct for still-water level. The tidal offset correction was done using the nearby tide gauge data at Visakhapatnam Harbour $\left(17^{\circ} 40^{\prime} 60^{\prime \prime} \mathrm{N}, 83^{\circ} 16^{\prime} 60^{\prime \prime} \mathrm{E}\right)$. The dataset was divided into calibration/training (10\%) and validation $(90 \%)$ sub-datasets for further analysis.

Sentinel-2A and $2 \mathrm{~B}$ are twin polar-orbiting satellites developed by the European Space Agency (ESA). Sentinel-2A was launched on 23 June 2015 and Sentinel-2B was launched 7 March 2017 as a follow-on mission. The radiometric, spectral and spatial specifications of both satellites are specified in the User Handbook ${ }^{17}$. Sentinel-2
level-1C (L1C) products covering the study sites were downloaded from the Sentinel's Scientific Data Hub. Cloud cover and ocean waves are the significant limiting factors in the selection of satellite data. A total of six scenes covering two study sites available closest to the field survey (24-25 October 2018) during the same season with low cloud cover, no sun glint, and calm sea state were selected for further analysis. All the images were acquired at high tide to ensure that inter-tidal areas were not exposed (Table 1). The images were processed to level-2A (L2A) using the latest ACOLITE (Python 20190326.0 version) processor developed by the Royal Belgian Institute of Natural Sciences, Belgium, which supports atmospheric correction specifically for the marine environment of both Landsat- 8 and Sentinel-2 data $^{18,19}$. It uses dark spectrum fitting (DSF) algorithm for atmospheric correction ${ }^{20}$, where aerosol correction is done by estimating atmospheric path reflectance from multiple dark targets within the scene and includes the sun glint correction. ACOLITE provides remote sensing reflectance (Rrs, 1/sr) data in all visible and near-infrared (NIR) bands resampled to $10 \mathrm{~m}$ spatial resolution.

The log-transformed band ratio method, a widely used algorithm for the estimation of SDB was employed with the 'SDBgreen' approach ${ }^{14,21}$, which is the ratio of blue to green band reflectances. The model utilizes the ratio of 
log-transformed water reflectances of bands having different water absorptions; so its ratio of reflectances will change with depth. The log transform accounts for the exponential decrease of light penetration with depth according to Beer's law ${ }^{22}$. Since blue and green bands have lower absorption, their ratio always remains the same despite the different bottom albedos at constant depth. Since Sentinel-2A and -2B have similar blue bands at $492 \mathrm{~nm}$ and green bands at $560 \mathrm{~nm}(559 \mathrm{~nm}$ for S2B) with the same spatial resolution of $10 \mathrm{~m}$, we implemented the ratio of blue $\left(\lambda_{\mathrm{b}}\right)$ and green $\left(\lambda_{\mathrm{g}}\right)$ bands to give the depth $\left(Z_{\mathrm{S} 2}\right)$ as follows

$$
Z_{\mathrm{S} 2}=m_{1} \mathrm{pSDB}-m_{0},
$$

where

$$
\mathrm{pSDB}=\frac{\ln \left(n \times \pi \times \operatorname{Rrs}\left(\lambda_{\mathrm{b}}\right)\right)}{\ln \left(n \times \pi \times \operatorname{Rrs}\left(\lambda_{\mathrm{g}}\right)\right)}
$$

Here, pSDB is the relative or 'pseudo' depth from the satellite (dimensionless), $Z_{\mathrm{S} 2}$ is the Sentinel-2-derived bathymetry $(\mathrm{m}), m_{1}$ and $m_{0}$ are tunable constants to linearly transform the algorithm results to the actual depths and $n=1000$ is considered to assure that logarithm results in a positive value under any condition and that the ratio produces a linear response over the retrievable water depth.

The turbidity and other noising effects (cloud shadows, glint, bubbles, waves, etc.) can have a significant impact on water-leaving reflectance and thus the derived water depth ${ }^{23,24}$. High turbidity can result in higher water leaving reflectances across the visible NIR channels overestimating the depths in shallow waters $(<6 \mathrm{~m})^{25}$ and underestimating in deeper waters $(6-10 \mathrm{~m})^{23}$. These effects produce false shoaling signatures in the bathymetry maps and reduce the accuracy of the retrievals ${ }^{14}$. To minimize the impact of signal noise, first a $3 \times 3$ pixel median filter was applied over the entire scene for all the bands considered. Then, all the scenes were compared to identify the maximum pSDB at the pixel level and a resultant composite image of maximum pSDB was created. As the study region falls under the meso-tidal area, we have constrained the input images to a common tidal level (tide range is almost the same for all scenes considered), so that the inclusion of tidal component in the bathymetry retrieval was automatically taken care of in the study. This approach is similar to that proposed by Caballero and Stumpf ${ }^{24}$; however, it differs in the number of scenes considered for processing. Caballero and Stumpf $^{24}$ had implemented the method over the clear waters of two islands for one year. Usually, island waters have uniform variability in clarity and sediment levels, whereas in the case of beach waters, several active processes are involved in resuspension of sediments in shallow depths. Hence, we propose to use only a few scenes of a season (generally with calm sea state and relatively clear water conditions) to create a multi-scene composite image for bathymetry retrieval. In this case, we considered the October-December 2018 period (Figure 2). Also, this period is considered as the most vulnerable due to rip current formation in the study $\operatorname{sites}^{26}$, and would help us locate rip channel formations from the maps.

During the calibration stage, bathymetry map with a uniform spatial resolution of $10 \mathrm{~m}$ was generated using eqs (1) and (2). The depth data were extracted from the satellite-derived depth data $\left(Z_{\mathrm{S} 2}\right)$ exactly at the same location where jet ski-based echo-sounder depths $Z_{\mathrm{JS}}$ are available. Later, $Z_{\mathrm{S} 2}$ depths were compared with $Z_{\mathrm{JS}}$ and separated into depth classes (Table 2). The difference maps were plotted for ROI-1 and ROI-2 (Figure $3 a$ and $b$ ). These maps were used to evaluate the relative error of SDB against the jet ski survey by assessing the spatial distribution of error (in terms of nearshore morphological features). To complement this assessment, five statistical parameters were computed ${ }^{27}$

$$
\begin{aligned}
& \text { Bias }=\text { Mean }\left(Z_{\mathrm{S} 2}\right)-\text { mean }\left(Z_{\mathrm{JS}}\right), \\
& \mathrm{RMSE}=\sqrt{\frac{\sum_{i=1}^{n}\left(Z_{\mathrm{S} 2}-Z_{\mathrm{JS}}\right)^{2}}{n},} \\
& \mathrm{MAE}=\frac{1}{n} \sum_{i=1}^{n}\left|Z_{\mathrm{S} 2}-Z_{\mathrm{JS}}\right|, \\
& \mathrm{MNB}=\frac{\sum_{i=1}^{n}\left(\frac{Z_{\mathrm{S} 2}-Z_{\mathrm{JS}}}{Z_{\mathrm{JS}}}\right)}{n},
\end{aligned}
$$

Difference $\operatorname{median}=\operatorname{Median}\left(Z_{\mathrm{S} 2}\right)-\operatorname{median}\left(Z_{\mathrm{JS}}\right)$.

Bathymetry maps of the two study sites were generated using the algorithm described in Figure 2. Rushikonda (ROI-1) corresponds to a bay-type beach and RK Beach (ROI-2) represents an open beach. There is clear evidence of multiple rip channel formation in ROI-1 (Figure $4 a$ ) along a sandbar with two relatively deeper zones in between. The same pattern is seen in the individual imageries of the data considered in the study (see Figure $1 \mathrm{c}$ ). The depth gradient is more in ROI-2, where the bottom drops suddenly unlike in the case of ROI-1. The data gap in the satellite-derived bathymetry between the coastline and the first depth point is due to the effect of wave breaking and suspension of bottom sediments.

The surveys were carried out on 24 and 25 October 2018 at Rushikonda and RK Beach, whereas Sentinel-2A/B 
RESEARCH COMMUNICATIONS

Table 2. Residual statistics between satellite-derived depth $\left(Z_{\mathrm{S} 2}\right)$ and jet ski depth $\left(Z_{\mathrm{JS}}\right)$ for different depth classes

\begin{tabular}{|c|c|c|c|c|c|c|c|c|}
\hline & \multicolumn{8}{|c|}{ Depth class (m) } \\
\hline & & $1(0-2)$ & $2(2-4)$ & $3(4-6)$ & $4(6-8)$ & $5(8-10)$ & $6(10-12)$ & Overall $(0-12)$ \\
\hline \multirow[t]{2}{*}{$N$} & ROI-1 & 1171 & 967 & 591 & 600 & 486 & 234 & 4066 \\
\hline & ROI-2 & 475 & 1095 & 1490 & 423 & 446 & 209 & 4138 \\
\hline \multirow[t]{2}{*}{ Bias (m) } & ROI-1 & 0.14 & 0.22 & 0.58 & -0.09 & -0.87 & -1.13 & -0.01 \\
\hline & ROI-2 & 0.34 & 0.18 & 0.30 & 0.11 & -0.98 & -1.66 & 0.02 \\
\hline \multirow[t]{2}{*}{ Root mean square error (m) } & ROI-1 & 0.98 & 1.35 & 1.09 & 0.67 & 1.06 & 1.26 & 1.09 \\
\hline & ROI-2 & 1.16 & 0.81 & 0.71 & 0.73 & 1.19 & 1.73 & 0.93 \\
\hline \multirow[t]{2}{*}{ Mean absolute error (m) } & ROI-1 & 0.65 & 0.91 & 0.76 & 0.52 & 0.93 & 1.14 & 0.77 \\
\hline & ROI-2 & 0.94 & 0.69 & 0.55 & 0.58 & 1.03 & 1.66 & 0.73 \\
\hline \multirow[t]{2}{*}{ Mean normalized bias (m) } & ROI-1 & 0.38 & 0.06 & 0.12 & -0.01 & -0.09 & -0.10 & 0.12 \\
\hline & ROI-2 & 1.49 & 0.05 & 0.06 & 0.02 & -0.11 & -0.16 & 0.19 \\
\hline \multirow[t]{2}{*}{ Difference median (m) } & ROI-1 & 0.04 & -0.03 & 0.51 & -0.15 & -0.92 & -0.97 & 0.67 \\
\hline & ROI-2 & 0.31 & 0.13 & 0.27 & 0.30 & -1.08 & -1.76 & 0.28 \\
\hline
\end{tabular}

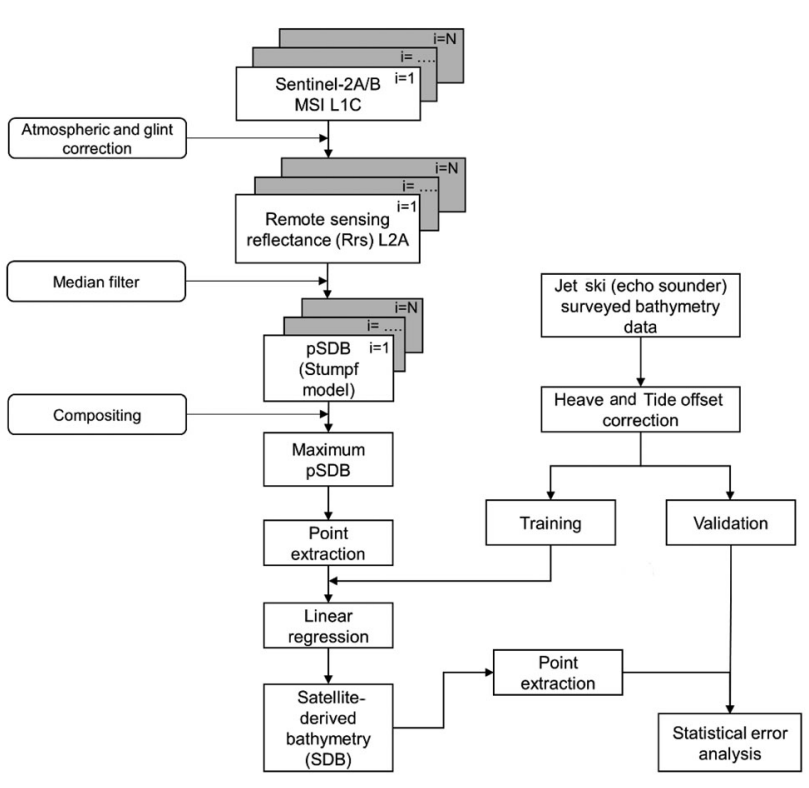

Figure 2. Schematic workflow of processing of Sentinel-2A and $2 \mathrm{~B}$ MSI data along with jet ski sounding depth data in the study area.

data were considered from 5 October to 24 December 2018. After excluding cloudy scenes and those with sun-glint effects and swells, six scenes were finally chosen for the study. It was assumed that shallow water bathymetry does not change much during the above period. The Sentinel-2-derived bathymetry estimates were evaluated using the remaining (90\% data) subset of independent jet ski-surveyed points. The spatial distribution $(N=4066$ for ROI-1, 4138 for ROI-2, combined $N=8204)$ of residuals between collocated estimated depths from composite S2A/B imageries and those obtained from the jet ski over two different regions of interest are shown in Figure 3 and Table 2 shows the error statistics. The data were separated into $2-\mathrm{m}$ class intervals to evaluate the strengths and drawbacks of the algorithm. The relative frequencies of error distribution over different classes were determined to analyse the differences between $Z_{\mathrm{S} 2}$ and $Z_{\mathrm{JS}}$ (Figure $3 c$ and $d$ ). Overall, the distribution of differences was confined within $\pm 1 \mathrm{~m}$, except for depths of class 6 (bias $=-1.13$ and $-1.66 \mathrm{~m}$; Table 2). The algorithm performed well in classes 2 to 4 , which cover a depth of 2-8 $\mathrm{m}$ with bias contained within $0.5 \mathrm{~m}$. However, class 1 covering a depth less than $2 \mathrm{~m}$ has higher root mean square error (RMSE) of 0.98 and $1.16 \mathrm{~m}$ for the two regions respectively, indicating the poor performance of the algorithm. Classes 5 and 6 show relatively higher values of bias $(-0.87$ to $-1.66 \mathrm{~m})$, mean absolute error (MAE) (0.93 to $1.66 \mathrm{~m}$ ), difference median $(-0.92$ to $-1.76 \mathrm{~m})$ and $\operatorname{RMSE}(1.06$ to $1.73 \mathrm{~m})$. The errors in the depth range $10-12 \mathrm{~m}$ are higher due to the inherent satellite problem, where the depth of light penetration is confined. Classes 1 to 4 comprising depth range 0-8 m include $82 \%$ ( $84 \%$ for ROI- 2 ) of the $N$ sampled points for validation, whereas classes 5 and 6 contain $18 \%$ in ROI-1 (16\% for ROI-2). The overall satellitederived bathymetry also showed a strong correlation with the field measurements according to the $R^{2}$ values of 0.88 at ROI-1 and 0.84 at ROI-2 (Figure 5). There are discrepancies between satellite-derived bathymetry and jet ski observations over the submerged rocky outcrops along the southern stretch of ROI-1 (Figure $1 c$ ), where SDB overestimated the depth by more than $2 \mathrm{~m}$ (Figures $3 a$ and $5 \mathrm{~b}$ ). The large positive prediction $(+2 \mathrm{~m})$ difference in SDB has also been observed by Cahalane et al. ${ }^{12}$, over particular areas characterized by hard grounds and coarse gravel. Therefore, different band combinations like green/red or blue/red can be used to evaluate the influence of band choice on accuracy in SDB retrieval.

This study presents the potential of Sentinel-2A and 2B imageries to map the nearshore bathymetry at $10-\mathrm{m}$ spatial resolution over two sites of variable beach morphologies along the east coast of India. Accurate SDB was derived by incorporating a robust atmospheric correction with ACOLITE, a multi-scene compositing approach to reduce the impact of water clarity, waves and turbidity effects. The overall performance of the log-transformed ratio algorithm of blue and green bands of Sentinel-2 was 

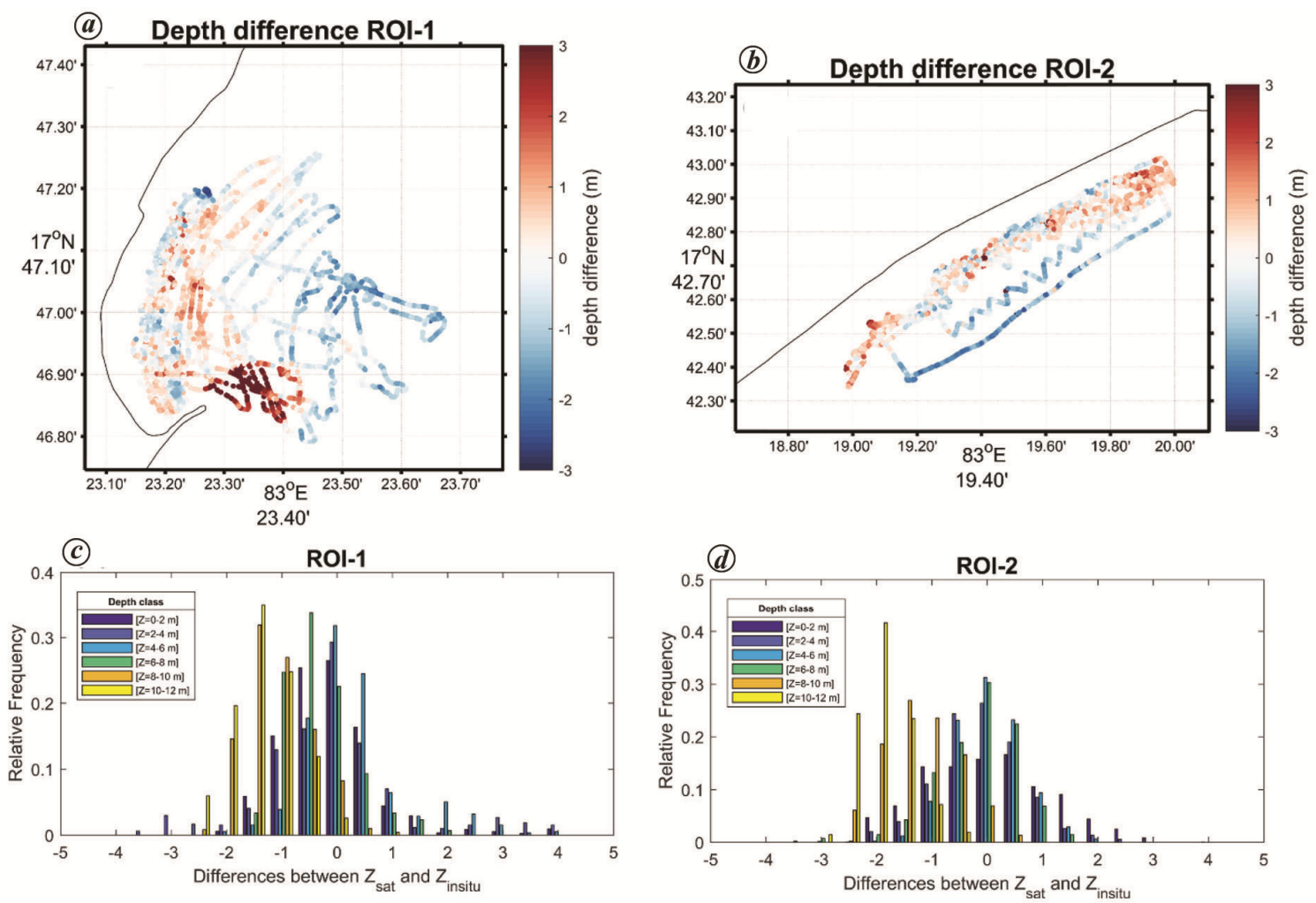

Figure 3. ( $\boldsymbol{a}, \boldsymbol{b})$ Spatial maps and $(\boldsymbol{c}, \boldsymbol{d})$ histograms of depth differences by depth class between satellite-derived and jet skisurveyed depths at ROI-1 and ROI-2 respectively. Coloured filled circles in $(\boldsymbol{a})$ and $(\boldsymbol{b})$ are the surveyed points used for validation.
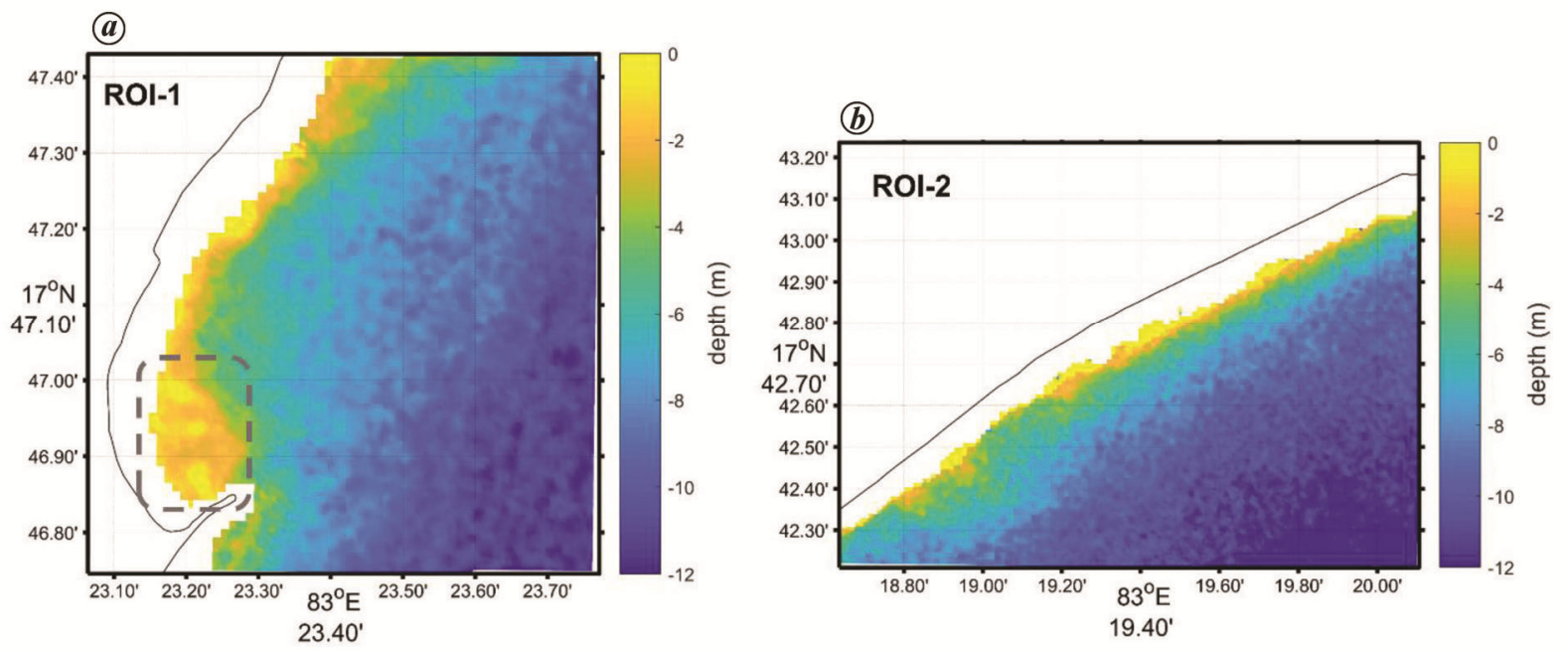

Figure 4. $\boldsymbol{a}$, Satellite-derived nearshore bathymetry maps at two sites. $\boldsymbol{b}$, The dotted rectangle in $(\boldsymbol{a})$ shows rip channels formed along an underwater sandbar in the bay.

assessed within the depth range $0-12 \mathrm{~m}$ and could achieve an overall error of $<1 \mathrm{~m}$, which is accepted by the research community. The model performed well over very shallow depths $(2-8 \mathrm{~m})$ with bias contained within $\pm 0.5 \mathrm{~m}$. However, this method has a major limitation that it requires few measured depths for training the SDB algorithm, which may not be possible for remote areas with less accessibility. With the recent launch of the
ICESat-2 lidar satellite, the requirement of in situ depths can be replaced with complete satellite-based measured depths for seeding to the SDB algorithm. In this study, the Sentinel-2 satellites capture small-scale features such as rip channels along sandbars relevant to coastal managers for beach safety. However, the algorithm could not perform well for $<2 \mathrm{~m}$ depth waters due to the combined effect of wave breaking and poor atmospheric correction. 

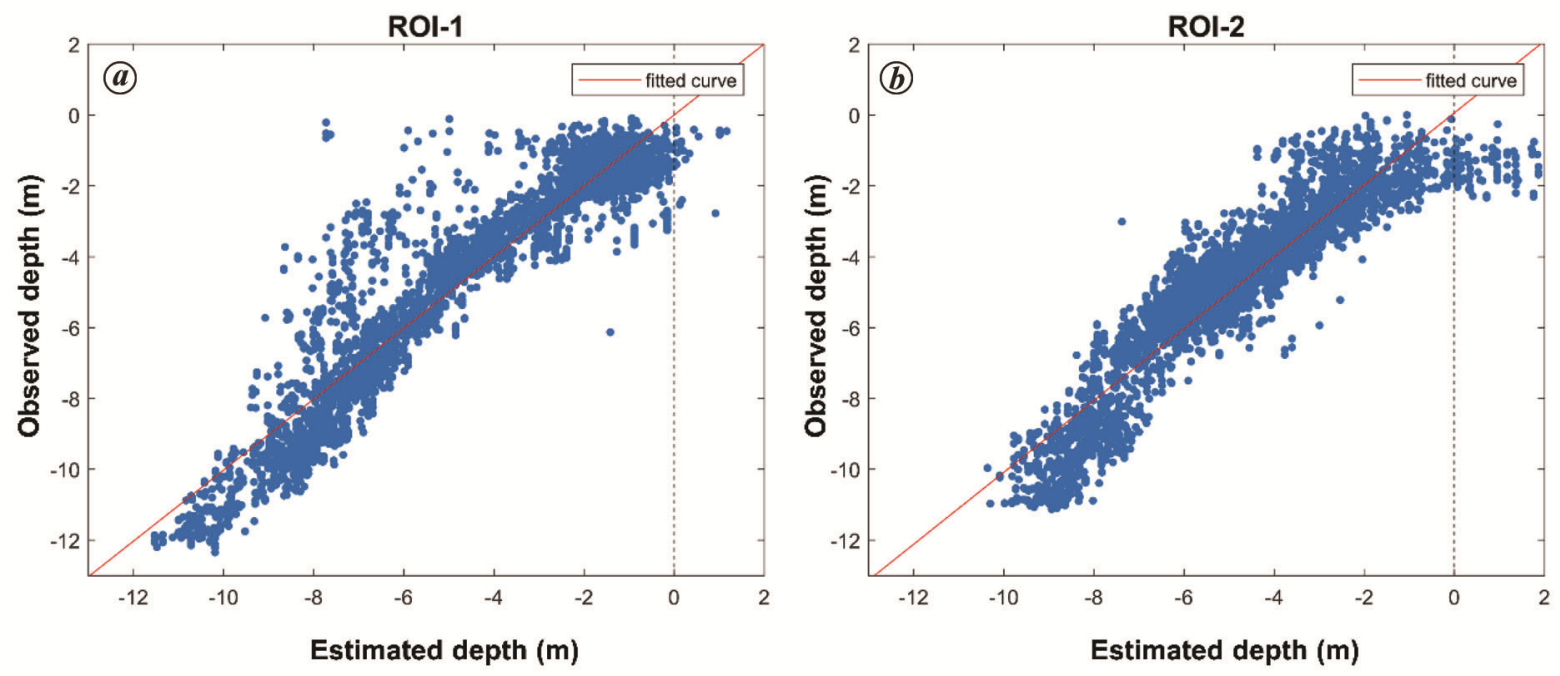

Figure 5. $\boldsymbol{a}$, Scatter plot between satellite-derived estimated depth and jet ski-observed depth for ROI-1 and ROI-2. $\boldsymbol{b}$, Red line indicates linear fit and dotted line indicates estimated zero depth.

The multi-scene approach of Sentinel-2 twin satellites highlights the extraction of nearshore bottom topography with the advantages of rapid processing and flexibility over wide areas without compromising the accuracy levels.

1. Dai, Z., Liu, J. T., Fu, G. and Xie, H., A thirteen-year record of bathymetric changes in the North Passage, Changjiang (Yangtze) estuary. Geomorphology, 2013, 187, 101-107.

2. Patgaonkar, R. S., Ilangovan, D., Vethamony, P., Babu, M. T., Jayakumar, S. and Rajagopal, M. D., Stability of a sand spit due to dredging in an adjacent creek. Ocean Eng., 2007, 34, 638-643.

3. Losi, V. et al., The use of nematodes in assessing ecological conditions in shallow waters surrounding a Mediterranean harbour facility. Estuarine Coast. Shelf Sci., 2013, 130, 209-221.

4. Nishida, T., Mohri, M., Itoh, K. and Nakagome, J., Study of bathymetry effects on the nominal hooking rates of yellowfin tuna (Thunnus albacares) and bigeye tuna (Thunnus obesus) exploited by the Japanese tuna longline fisheries in the Indian Ocean. IOTC Proc., 2001, 4, 191-206.

5. Basu, A. and Malhotra, S., Error detection of bathymetry data by visualization using GIS. ICES J. Mar. Sci., 2002, 59, 226-234.

6. Ridente, D., Martorelli, E., Bosman, A. and Chiocci, F. L., Highresolution morpho bathymetric imaging of the Messina Strait (Southern Italy). New insights on the 1908 earthquake and tsunami. Geomorphology, 2014, 208, 149-159.

7. Bailly du Bois, P., Automatic calculation of bathymetry for coastal hydrodynamic models. Comput. Geosci., 2011, 37, 1303-1310.

8. Noone, K. J., Sumaila, U. R. and Diaz, R. J., Managing Ocean Environments in a Changing Climate 1st Edition, Sustainability and Economic Perspectives, Elsevier, Newness, 2013.

9. Kumar, R., Sarkar, A. and Pandey, P. C., Estimation of ocean depths off Goa coast using ERS-1 Synthetic Aperture Radar. Cont. Shelf Res., 1999, 19, 171-181.

10. Brusch, S., Held, P., Lehner, S., Rosenthal, W. and Pleskachevsky, A., Underwater bottom topography in coastal areas from TerraSAR-X data. Int. J. Remote Sensing, 2011, 32, 4527-4543.

11. Mishra, M. K., Ganguly, D., Chauhan, P. and Ajai, Estimation of coastal bathymetry using RISAT-1 C-Band microwave SAR data. IEEE Geosci. Remote Sensing Lett., 2014, 11, 671-675.
12. Cahalane, C., Magee, A., Monteys, X., Casal, G., Hanafin, J. and Harris, P., A comparison of Landsat 8, Rapid Eye and Pleiades products for improving empirical predictions of satellite-derived bathymetry. Remote Sensing Environ., 2019, 233, 111414.

13. Li, J. et al., Adaptive bathymetry estimation for shallow coastal waters using Planet Dove satellites. Remote Sensing Environ., 2019, 232, 111302.

14. Caballero, I. and Stumpf, R. P., Retrieval of nearshore bathymetry from Sentinel-2A and 2B satellites in South Florida coastal waters. Estuarine Coast. Shelf Sci., 2019, 226, 106277.

15. Surisetty, V. V. A. K., Luhar, R., Sharma, R. and Kumar, R., Design and development of low-cost GNSS based drifter for studying rip currents. Curr. Sci., 2020, 118, 273-279.

16. Dugan, J. P., Morris, W. D., Vierra, K. C., Piotrowski, C. C., Farruggia, G. J. and Campion, D. C., Jet ski-based nearshore bathymetric and current survey system. J. Coast. Res., 2001, 17, 900-908.

17. ESA, SENTINEL-2 User Handbook, European Space Agency, 2015.

18. Vanhellemont, Q., Dogliotti, A. I., Nechad, B., Pringle, N. and Van der Zande, D., New opportunities and challenges for high resolution remote sensing of water colour. Ocean Optics 2016 Conference, 2016.

19. Vanhellemont, Q. and Ruddick, K., Acolite for Sentinel-2: Aquatic Applications of MSI Imagery, ESA, Belgium, 2016, SP-740, pp. 9-13.

20. Vanhellemont, Q. and Ruddick, K., Atmospheric correction of metre-scale optical satellite data for inland and coastal water applications. Remote Sensing Environ., 2018, 216, 586-597.

21. Stumpf, R. P., Holderied, K. and Sinclair, M., Determination of water depth with high resolution satellite imagery over variable bottom types. Limnol. Oceanogr., 2003, 48, 547-556.

22. Gao, J., Bathymetric mapping by means of remote sensing: methods, accuracy and limitations. Prog. Phys. Geogr., 2009, 33, 103-116.

23. Casal, G., Monteys, X., Hedley, J., Harris, P., Cahalane, C. and McCarthy, T., Assessment of empirical algorithms for bathymetry extraction using Sentinel-2 data. Int. J. Remote Sensing, 2019, 40, 2855-2879.

24. Caballero, I. and Stumpf, R. P., Towards routine mapping of shallow Bathymetry in environments with variable turbidity: contribution of Sentinel-2A/B satellites mission. Remote Sensing, 2020, 12, 451 . 
25. Bramante, J. F., Raju, D. K. and Sin, T. M., Multispectral derivation of bathymetry in Singapore's shallow, turbid waters. Int. J. Remote Sensing, 2013, 34, 2070-2088.

26. Surisetty, V. V. A. K. and Prasad, K. V. S. R., Rip current-related fatalities in India: a new predictive risk scale for forecasting rip currents. Nat. Hazards, 2014, 70, 313-335.

27. Brando, V. E., Anstee, J. M., Wettle, M., Dekker, A. G., Phinn, S R. and Roelfsema, C., A physics based retrieval and quality assessment of bathymetry from suboptimal hyperspectral data. Remote Sensing Environ., 2009, 113, 755-770.

ACKNOWLEDGEMENTS. We thank the Director, Space Applications Centre (SAC, ISRO), Ahmedabad for support and encouragement, and Dr A. S. Rajawat, Group Director (Geosciences, Hydrology and Cryosphere Applications Group) for his suggestions and encouragement. We also thank the European Space Agency and the Copernicus programme for the Sentinel-2A and $2 \mathrm{~B}$ imageries; the Royal Belgian Institute of Natural Sciences, Belgium for providing ACOLITE processing software, and Tourism Department, Visakhapatnam and Andhra University for cooperation during field campaigns. This work is supported under an on-going SAMUDRA TDP R\&D project at SAC (ISRO).

\section{Biogenesis of silver nanoparticles by marine bacteria Labrenzia sp. Mab 26 associated with Isochrysis galbana}

\author{
S. V. Sandhya ${ }^{1,2}$ and K. K. Vijayan ${ }^{3, *}$ \\ ${ }^{1}$ Marine Biotechnology Division, Central Marine Fisheries \\ Research Institute, Cochin 682 018, India \\ ${ }^{2}$ Present address: Biological Oceanography Division, \\ CSIR-National Institute of Oceanography, Dona Paula 403 004, India \\ ${ }^{3}$ Central Institute of Brackishwater Aquaculture, \\ Chennai 600 028, India
}

The metabolic or chemical nature of algal-bacterial interactions has opened up unexpected new ways for finding novel microbes with potential for several biotechnological applications. Silver nanoparticles (AgNps) possess many unique and attractive properties which are beneficial to various industries. In this context, the present study was undertaken to explore the bacterial strain Labrenzia sp. Mab 26, isolated from marine microalgae, Isochrysis galbana for AgNp biosynthesis. The synthesized AgNps were further characterized by UV-Vis spectroscopy, XRD analysis,

*For correspondence. (e-mail: kkvijayanmbtd@gmail.com; vijayankk@gmail.com)
FT-IR spectroscopic analysis and electron microscopy. This shows that microalgae-associated bacteria can be explored for efficient synthesis of AgNps.

Keywords: Algal-bacterial interaction, biogenesis, Isochrysis galbana, Labrenzia species, silver nanoparticles.

THE marine environment has proven to be an untapped reservoir of diverse natural products with potent biological activities ${ }^{1,2}$. Among marine organisms, microalgae represent one of the richest sources of valuable bioactive compounds for various industrial applications ${ }^{3-5}$. Bacterial communities in the algal phycosphere have been extensively studied ${ }^{6-8}$. It has been suggested that these microbial symbionts produce a wide range of bioactive compounds and thus create a suitable chemical microenvironment with their phytoplankton host. These metabolic associations thus make it challenging to understand which partner entity is accountable for the production of a particular metabolite ${ }^{1}$. Moreover, the associated bacteria may have a greater potential to produce bioactive agents than those of their free-living counterparts ${ }^{9,10}$. Thus, these symbiotic or commensal bacteria could be expected to be a remarkable source of valuable compounds with prospective benefits for humans. However, the biological wealth of bacteria associated with marine microalgae is relatively unexplored. In this background, the present study aims to explore the emerging application of culturable bacteria associated with marine microalgae for silver nanoparticle $(\mathrm{AgNp})$ biosynthesis.

The bacterial strain, Labrenzia sp. Mab 26 (GenBank accession no KR004822; strain code of the isolate starts with MBTDCMFRI) which was isolated from marine microalgae culture, Isochrysis galbana (MBTDCMFRI S002) and preserved at the microbial culture collection of the Marine Biotechnology Division, Central Marine Fisheries Research Institute (CMFRI), Cochin, Kerala, India was used for this study ${ }^{8}$. The bacterial strain was grown in Zobell marine broth (ZMB, HiMedia, India) and incubated at room temperature for $48 \mathrm{~h}$. After incubation, the biomass was separated by centrifugation (8000 rpm, 15 min; Remi, India). The culture supernatant was then mixed with an equal quantity of $5 \mathrm{mM}$ silver nitrate solution (prepared in sterile distilled water) and kept in a shaker for three days at room temperature. Sterile ZMB mixed with silver nitrate solution was kept as control. Biosynthesis of AgNps was observed by a colour change $^{11}$.

The formation of AgNps was studied by UV-Vis spectroscopy (Thermo Scientific, USA). $\lambda_{\max }$ was determined within the range $300-800 \mathrm{~nm}$. The sample was centrifuged $(10,000 \mathrm{rpm}, 20 \mathrm{~min})$ and the pellet was freezedried for further analysis. The crystalline nature of the synthesized AgNps was determined by X-ray diffraction (XRD) analysis (Bruker, D8 Advance, Germany). Nicolet 